\title{
Sustainability Transitions: Exploring Risk Management and the Future of Adaptation in the Megacity of Lagos
}

\author{
Idowu Ajibade*, Mark Pelling, Julius Agboola \\ and Matthias Garschagen \\ Balsillie School of International Affairs \\ 67 Erb Street West, Waterloo, ON N2L 6C2, Canada \\ *jajibade@balsillieschool.ca
}

Accepted 16 November 2016

Published 21 March 2017

\begin{abstract}
Lagos, a coastal megacity with more than 11 million inhabitants faces serious development challenges in addition to climatic risks and extreme weather events. There are uncertainties about future disaster risk trends and about how to manage and adapt to existing threats in ways that ensure a just and sustainable development trajectory. In this paper, we explore the changes that have occurred in risk management in Lagos over the last 20 years, as part of a broader endeavor towards sustainability. We draw on transition theory to analyze data collected from a scenario workshop and expert interviews conducted over a period of two years, to understand the influences, processes and actors that shape the adaptationdevelopment nexus in Lagos. Findings based on stakeholders voices present a risk management regime firmly oriented towards protecting contemporary development gains and policies, despite Nigeria's contested development strategy. Future positioning of risk management is described as either maintaining its current goals or shifting towards a position where development is seen as a root cause of risk and a focus for change. Resilience (marginal changes in development to maintain stability) is not foreseen as a likely future choice for Lagos. This is in contrast to many global agendas that promote resilience and reflects the realities of managing risks in the context of contested development.
\end{abstract}

Keywords: Climate change adaptation; development; Lagos; rise management; sustainability transition; transformation; resilience.

${ }^{*}$ Corresponding author.

This is an Open Access article published by World Scientific Publishing Company. It is distributed under the terms of the Creative Commons Attribution 4.0 (CC-BY) License. Further distribution of this work is permitted, provided the original work is properly cited. 


\section{Introduction}

Over the last decade, the study of sustainability transitions has gained increased prominence in climate change studies and urban policy research (Bulkeley et al. 2010; World Bank 2012). Within the climate change mitigation literature, transition studies in cities have focused on how societies shift from a locked-in industrial development trajectory to a low-carbon future by exploring issues related to fossil-fuel consumption, energy security, air pollution, natural resource depletion, green economies and renewable energy targets (Jefferson 2008; Bridge et al. 2013). From the perspective of adaptation, transition research focuses on the autonomous or planned processes that can create pathways towards social transformation for a more just and sustainable development (Pelling et al. 2015; Tschakert et al. 2016). This involves understanding the dynamic interactions between a broad range of economic, social, ecological and political processes together with the role of actors, policies and institutions that shape how societies change, remain redundant or move towards a better and more secure future in response to, or in spite of, climatic risks. In countries across the world, proactive and reactive adaptation strategies are already being implemented, however, it is not clear which of these strategies will lead to sustainability or open up opportunities for transition to alternative development pathways. This is particularly so in the Global South (Heltbergs et al. 2009; Eriksen et al. 2011) where interventions have been found to exacerbate vulnerability and social inequality (Ajibade, 2013; Anguelovski et al. 2016). To be clear, transition in coastal cities of the global south is often entwined with other pressing problems of weak governance, corruption, population pressure, aging infrastructure, inappropriate land-use, insecurity, and poverty, together with a higher susceptibility to extremes events such as floods, storm surges, heat waves, and sea level rise. Knowledge about how these existing pressures and climatic hazards can be managed within the rubric of risk management coupled with adaptation planning will shape the future of urban development and also influence the capacity for a sustainability transition.

In this paper, we explore risk management and adaptation as part of a broader transitional endeavor towards sustainable development. We utilize models of policy regime-shifts in risk management and ideas from transition theory to understand the practice and goals of adaptation, and their relationship with urban development trajectories. We pay particular attention to the role of leadership, vision and new institutional arrangements in urban governance; focusing on the extent to which these elements can trigger a shift that opens up options for future transitions (institutions are understood here as organizations as well as established rules and norms that shape and influence socialized ways of interacting). Specific 
insights are drawn from the case study of Lagos, a coastal megacity and regional growth engine in Nigeria, West Africa. As part of our research objectives, we aim to also answer the following questions:

1. In what ways does current risk management policy in Lagos intersect with climate change adaptation and urban development?

2. Is there evidence that transition to a new risk management paradigm is desirable among practitioners?

3. If there is a desire for transition how will this be enabled or constrained by current actors and policy architecture for adaptation and risk management in the city of Lagos?

The rest of this paper is divided into five sections. In Section 2, we provide an overview of climate risks and vulnerabilities in Lagos, followed by our research method, a theoretical framework on transition, and then the presentation of results and conclusion.

\section{Lagos: Climatic Risks and Vulnerabilities}

Lagos, the largest commercial and industrial city in Nigeria, is exposed to intense rainfall, heatwaves, coastal flooding, storm surges and sea level rise. At the same time, the city faces high and uneven levels of vulnerability rooted in macroeconomic fragility, mass poverty, population pressure, and insufficient infrastructure and housing. A study conducted in 2011, predicts a conservative warming of 1 to $2^{\circ} \mathrm{C}$ for Lagos and between 5 to $50 \mathrm{~cm}$ sea level rise by 2100 (Rosenzweig et al. 2011). Increased temperature in the city could compound local air pollution and also heighten the likelihood of heatwave-related morbidity and mortality (WHO 2009; Kjellstrom et al. 2010). Frequent and intense rainfall often exacerbated by the city's waste accumulation and inadequate drainage systems place populations at greater risk of the health impacts of flooding and economic loss associated with displacement and property damage (Ajibade and McBean 2014; Ajibade et al. 2013).

Coastal erosion and storm surges are serious concerns for communities and industries located on the coast. Erosion problems in Lagos have been intensified by the frequent occurrence of storm surges in Victoria Island (Olaniyan and Afiesimama 2003). During a storm surge, the wavelength along the Bar Beach, which normally ranges from $0.9 \mathrm{~m}$ to $2 \mathrm{~m}$, can exceed $4 \mathrm{~m}$, resulting in traffic disruption and flooding of residential and offices spaces (Nwilo 1997; Awosika et al. 2000). Sand filling and groynes construction used to protect the natural littoral drift at the Bar Beach are continually washed away by storm surges, thus 
contributing to an annual erosion rate of $25-30 \mathrm{~m}$ (Rosenzweig et al. 2011). Increased storminess in Lagos could cause salt-water intrusion into freshwater sources, disrupt ecosystems, change migration patterns of fish (possibly reduce fish resources) and displace coastal communities (Ekanade et al. 2011). Sea level rise is also a major concern for Lagos. The average elevation of the city is $1.5 \mathrm{~m}$ particularly around low-lying areas with high real estate values such as Victoria Island, Ikoyi, and Lekki. A rise in sea level of up to $50 \mathrm{~cm}$ coinciding with a storm surge could affect millions of people in these areas and potentially damage multimillion dollar businesses, infrastructure, and properties. These threats warrant an effective risk management strategy and a robust forward looking adaptation plan. Without such a plan or strategy, the impacts of climate change combined with multiple socio-economic pressures could undermine years of development in Lagos and hinder the city from transitioning towards sustainability.

\section{Transition Theory, Risk Management and Adaptation}

\subsection{Socio-technical transition and adaptation}

A number of theoretical frameworks are influential in transition studies; these include technological innovation systems (Hekkert et al. 2007), multi-level perspectives (MLP) on socio-technical transitions (Geels 2002; Smith et al. 2010), strategic niche management (Raven and Geels 2010), and transition management (Loorbach 2010). In this paper, we adopt an MLP approach to help make sense of the socio-technical transition dynamics that connect risk management and adaptation to sustainable development. Under MLP, transition is considered as the reconfiguration of institutional and organizational structures and systems of society. This unfolds over a long-term process (e.g., 40-50 years) with actors engaged in unpredictable ways alongside the complex landscapes of technology, policy, regulations, scientific knowledge, social practices and cultural values (Geels 2002; Swilling and Annecke 2010; Newell and Mulvaney 2013). Geels (2010) proposed three analytical levels for MLP: niches (the local sites where innovation arises), socio-technical regimes (mid-level context including city governance), and the socio-technical landscape (high level, global processes and flows). Transitions occur through interacting process within and between these levels (Geels 2010).

Transitions may be fast or slow, planned or surprise, intentional or forced, and are often associated with tipping points (i.e., moments of system alteration where rapid change could take place) (Pelling et al. 2017). The transition from one stable socio-technical regime to another occurs when regimes are destabilized. This can be triggered by changes in landscape pressure acting on regimes to mainstream niche innovation (Geels and Schot 2007). Openings for transition have also been 
observed following political (Pelling 2010) and institutional (Kemp et al. 2007) change, and can as well be a product of organic coevolution.

In climate change and urban development contexts, risk management and adaptation play an important role in sustainability transitions. The risk management process involves acting on decisions under conditions of uncertainty and threats (Jones and Preston 2011). In urban development, risk management seeks to enhance the capacity of cities, infrastructural systems, and urban populations to anticipate, respond and recover quickly and effectively from natural and man-made hazards; of which climate change represents one particular threat (Leichenko 2011). Disaster risk reduction places risk management within development policy and identifies the need to address the root causes of disasters as well as its local expressions in vulnerability and loss (UNDP 2004). Adaptation has revisited this argument and offers a similarly broad perspective on assessing and managing climatic risks and uncertainties. In this paper, adaptation refers to risk reduction that can address the root causes and manifestations of vulnerability as part of building a socio-ecologically sustainable and inclusive society (Wise et al. 2014). This conceptualization of adaptation inspired by Wise et al. (2014) builds on a long tradition of integrated disaster risk reduction (O’Keefe et al. 1976; Hewitt 1983; Wisner et al. 2004) and more recently on adaptation thinking which acknowledges that climate adaptation is not separable from the cultural, political, economic, environmental and developmental contexts in which it occurs but a part of a range of societal responses to change (Schipper et al. 2006; Taylor 2014; Wise et al. 2014).

Adaptation may involve incremental as well as transformative change aimed at meeting the proximate and root causes of risk (Moser and Ekstrom 2010). Identification of when transformation may arise in response to the coupled pressures of risk and opportunities for development is not always easy. Of particular relevance is the interplay between actors and decision-making processes (or in the language of socio-technological transitions, between niche and regime). These interactions accelerate, direct or prevent transitions which are always negotiated over unequal divisions of power and influence. The revisiting of risk management in an era of climate change impacts is an opportunity to more clearly surface its contribution to development and sustainability transitions (Pelling et al. 2017).

\subsection{Regime-shifts and risk management}

A key issue regarding transition across risk management paradigms is whether observed adjustments in policy, user practices, new technologies and institutional changes represent evidence of a shift towards a well-adapted society. If they do, when is a regime transition appropriate? What types of regime states can occur? Who are the dominant actors that can trigger a transition and is it possible to utilize 
transition windows to enhance equity and future risk reduction? Solecki et al. (2017) propose a framework that reflects four regime states in risk management [collapse, resistance, resilience and transformation] that we draw upon in this paper. They defined collapse as a regime state where there is a lack of formal planning, action and strategic oversight in managing risk — although this gap may signify a window of opportunity for innovation. Resistance prioritizes stability and persistence of dominant economic, political and physical systems as the goal of risk management and may deploy enormous resources towards the preservation of established systems and structures. Resilience is similar to resistance but confers flexibility and change at the margins of existing systems. Transformation describes a regime focused on fundamental change - where development processes, practices and structures are the target of risk management, not the objects to be protected by risk management (Solecki et al. 2017). Transformation, therefore, is concerned not only with risk management but with the larger political economy of a system (e.g., a city) as it relates to a broad set of interrelated outcomes - practical, political and socio-ecological (Pelling 2010). A transformative regime may evolve from radical disruptive shifts or through incremental adjustments where these adjustments are not short-term palliatives to avoid deep-rooted changes (Matyas and Pelling 2015).

Transitions between regime states may not happen easily. Existing regimes are stabilized by path-dependency and lock-in mechanisms that work to preserve vested interests, behavioral patterns, infrastructure, institutional culture and regulation oriented towards incremental innovation along a predictable pathway (Geels 2010). Internal and external drivers may trigger a transition. External drivers include focusing events (such as major floods and storms), while internal ones, particularly for a deliberate transformation of a system, will include strong leadership, effective and adaptive institutions, favourable public values and attitudes, and socially acceptable options plus incentives and resources for action (O’Brien 2012). As new risks emerge and old ones are exacerbated, a regime transition can maximize the solution space for risk management (Pelling et al. 2015).

\section{Research Method}

Data for this study were collected using a scenario workshop and semi-structured expert interviews conducted with urban planners, risk and emergency managers, city administrators, environmentalists, local government authorities and academics. The scenario workshop conducted in July 2014 included 25 participants. The aim of the workshop was to provide a space for facilitated reflection on urban planning and the role of risk management in development processes. Participants were asked to identify the most fundamental development trend that characterized 
Lagos and would likely inform its future development trajectory. Participants then used policy sectors such as housing, environment, physical planning, infrastructure, emergency management and transportation, to illustrate adaptive and maladaptive futures at the extreme ends of this development trend. In this way it was possible to explore the adaptation-development nexus, to arrive at a description of a contemporary and desired position and open conversation on how far the direction of travel implied by the fundamental development trends would enable or constrain movement to the more desired adaptation-development state (see Garschagen et al. 2017 for a detailed description of the method). Expert interviews with 19 participants were conducted between January and March 2016 through purposive sampling, in part connecting back to participants of the earlier workshop. Questions were asked about: climatic hazards and risk trends; actors and influences orienting the contemporary risk management regime; and factors that enable or constrain potential for regime transition. Using these two research techniques allowed for the co-production of knowledge and for triangulation of findings. Data were analyzed through the use of inductive approaches and manual coding techniques.

\section{Results}

This section presents the results of the three overarching research questions raised in this paper. We show the extent to which risk management in the city of Lagos is headed for a transition from one regime to another and how this process relates to overall development trends in the city.

\subsection{In what ways does current risk management policy intersect with climate change adaptation and urban development?}

\subsubsection{Resistance regime and weak governance}

The findings of the scenario workshop and expert interviews suggest that the prevailing orientation of risk management in Lagos is resistance: to protect people, properties and businesses while providing stability so that current development and economic activities are not undermined by everyday chronic risks and climatic extremes. At the same time, participants felt that the city's overall development has been strongly shaped by weak governance and the absence of a coherent government influence to steer development towards sustainability. The city's contemporary dysfunction was seen to date back to the industrialization process of the late 1960s when Lagos witnessed unprecedented infrastructural development, population explosion, high environmental pollution, and weak land-use planning and city management. In this sense, the overall political economy of urbanization 
in Lagos was seen to have produced the dominant drivers of the city's current vulnerability to natural hazards and climate change threats. These drivers include rural-urban migration, a lack of coherent land-use planning, investment-driven land reclamation in flood-exposed areas, high social inequality and poverty, weak institutions, and the lack of data and information on development parameters and hazard patterns that might inform proper planning.

Figure 1 offers the results of the scenario workshop with the adaptation-development nexus presented in four scenarios. Participants identified a movement between a laissez-faire [anything goes] governance regime characterized by unplanned and uncoordinated urbanization and a 'rigid and structured' governance regime with stronger rule-of-law and enhanced strategic planning and enforcement.

This trend was seen to be of major importance not only for overall socioeconomic development but also for risk management and adaptation. Participants desired a transition from the current laissez-faire mal-adapted status quo towards a more structured governance delivering an adaptive city. The rationale was that the latter would allow for a strategic and integrated planning on risk management

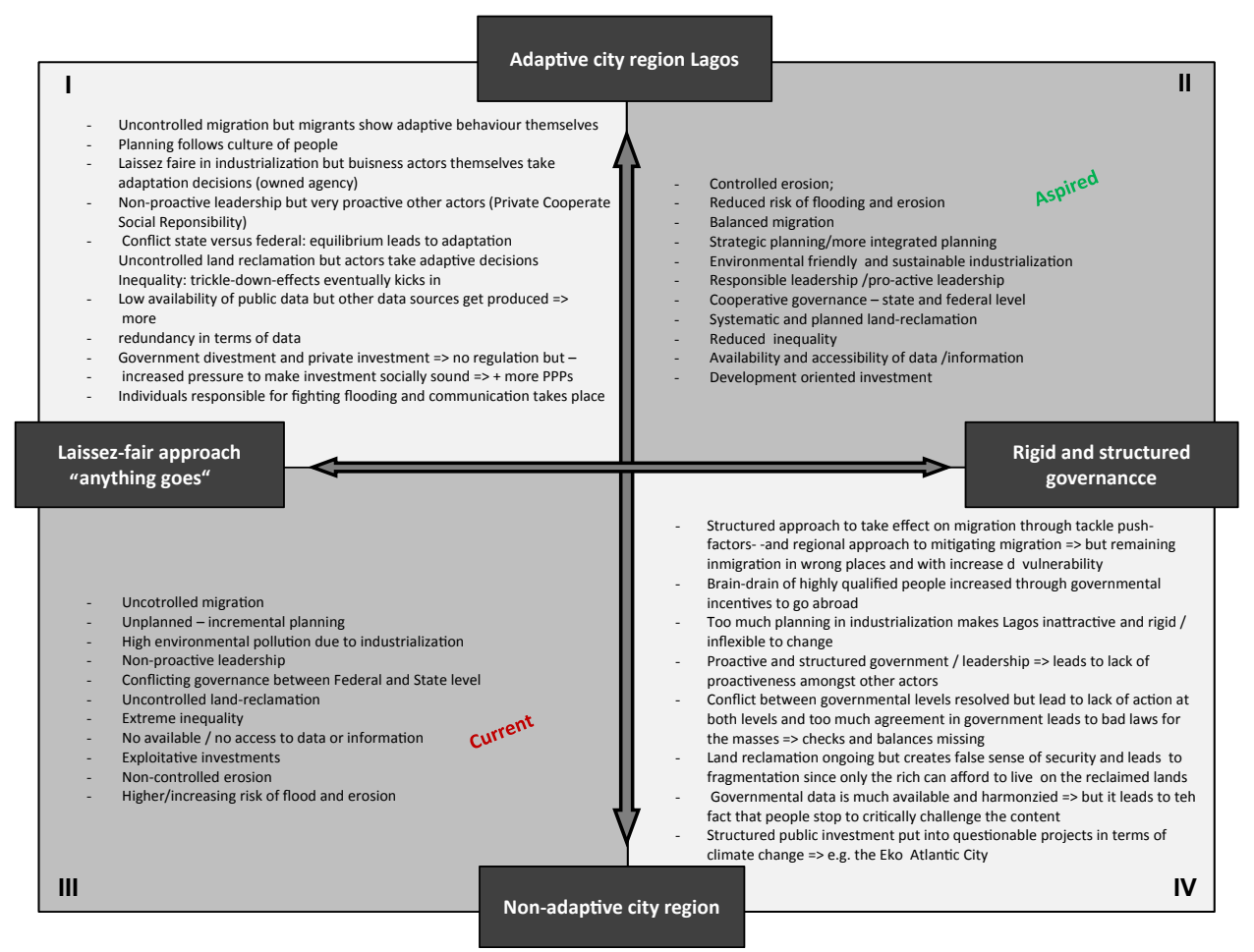

Figure 1. Climate Change Adaptation and Development Scenarios for Lagos 
(especially floods and erosion), together with a balanced migration pattern, reduced poverty and social inequality, systematic and planned land reclamation, and an environmentally friendly and sustainable development pathway under the guidance of a responsible and proactive leader (Figure 1). Participants agreed that such a transition would imply a comprehensive and transformative agenda but were very skeptical of the likelihood of such a change happening soon. Respondents from the expert interview echoed some of these insights and considered that social protection and an "increase in spaces of [personal] security" were crucial to reducing risk and securing an adaptable environment where development flourishes and people thrive. An expert from the Fire Service with several years of experience in emergency response stated that:

"The Lagos State government needs a policy on social protection that would focus more on the welfare of the poor including the provision of housing support, economic empowerment and infrastructural development. The aged, especially, will need government support and medical services to cope with risks”

\subsubsection{Housing, coastal risks and policy options}

Inadequate social intervention especially on housing support for low-income groups is a perennial problem in Lagos. Rapid population growth, limited land spaces and minimal to no government or corporate financing of mass housing for the poor are, in part, responsible for this problem. To date, two-thirds of Lagosians live in informal settlements that are predisposed to climatic risks and extreme weather events. These risks sit at the interface of the natural and built environment - they occur because urban development channels rainwater in hazardous ways towards people located on marginal sites where existing substandard housing, together with inadequate sewage and storm-water infrastructure, exacerbate vulnerability (Ajibade and McBean 2014). Untarred dilapidated roads and poor access to social services in these settlements also lead to reduced coping and adaptive capacity, thus creating a vicious circle of vulnerability for already disadvantaged groups. With climate change expected to increase the frequency and intensity of extreme weather events, managing future risks equitably and effectively in lowlying communities in close proximity to swamps (such as Badia and Makoko) and lagoons (such as highbrow areas of Lekki and Victoria Island) may force a transition from the current resistance regime towards resilience or possibly transformation.

Policy options that can trigger a transition in coastal risk management include voluntary mass resettlement, managed retreat, and planned coastal land reclamation. 
Voluntary mass resettlement has significant cost implications (social, political and financial) which the Lagos State government may be unable or unwilling to incur. For instance, land-for-land or land-for-housing compensation may not be feasible due to limited resources. The loss of attachment to place and loss of community cohesion may also pose as social barriers to voluntary resettlement. The second option, managed retreat, may be required in areas close to the Atlantic Ocean such as Badore, Lekki, and Victoria Island. However, the high land values in these areas make the economic case unattractive. Also, uncertainty about when and where sea level rise will have the greatest impact makes it difficult for policy makers to support the idea, since the benefits of a retreat strategy may not be accrued for many years. The last option, coastal land reclamation, has the potential benefit of increasing property and land values. This option was far more attractive to the government and land developers in Lagos. Recently, the Lagos State government embarked upon a series of land reclamation projects including the controversial ongoing Eko Atlantic City (EAC) project located as an appendage to Victoria Island along the Bar Beach shoreline of the Atlantic Ocean. Experience suggests that land reclamation projects tend to accelerate urbanization in flood-prone areas and reproduce risks by locking development into dangerous pathways. Participants from the scenario workshop noted that the land reclamation adaptation strategy in Lagos merely gives "false security to private owners and often leads to social fragmentation since only the rich can afford the newly reclaimed lands".

\subsubsection{Stable urban development and spaces of personal security}

Expert interview respondents identified "increase in spaces of security" as an important element for climate adaptation and a stable urban development in Lagos. This originated from a desired reduction in everyday chronic risks such as urban violence, building collapse, fire outbreak, and street crimes which have direct implications for human security. Poverty, rising unemployment and violence among restive youths (otherwise known as 'area boys') aggravate street crimes especially during rainy season. For example, a higher rate of street crimes such as theft and armed robbery were reported during heavy flooding which affected vehicular movement and caused traffic on major roads to slow down thus exposing travelers to attack. Such criminal acts concentrated vulnerability and insecurity among already distressed populations. A policy advisor concerned about the intersecting problems of population pressure, street crime and climate risks said:

"It is expected according to the Lagos State Bureau of Statistics that about six hundred thousand $(600,000)$ people come into Lagos daily. This has been attributed to the increased spate of 
crime. We also see that in 2008, 2011, 2012 and 2013 extreme rainfall led to flooding that put a lot of businesses and household at risk and there were thefts and loss of property"

Policy transitions in the security sector of Lagos signify a positive trend and more recently have been linked to risk management and adaptation. In 1996, the military administration of Colonel Buba Marwa introduced an anti-crime squad called Operation Sweep as well as Neighbourhood Watch to control crime rates and improve human security in the city. Having yielded little result, the subsequent government, under the leadership of Bola Tinubu in 1999 and Babatunde Fashola in 2007, made radical policy changes and security sector reforms. These reforms included: the establishment of the Lagos State Security Trust Fund (LSSTF) to enhance capacity and training of police officers; creation of a surveillance and command center with 24-hour emergency hotlines; provision of patrol vehicles for law enforcement agents; installation of streetlights on major roads and streets; and an aggressive greening and beautification of open spaces and recreation parks across the city. Collectively, these efforts have raised public confidence in urban governance and have changed the perception of Lagosians from assuming personal responsibility for their own security to seeing it as a public good and an integral part of urban development and adaptation. The director of technical programs department considered these changes in the security sector as a regime-shift in risk management that occurred in the last 16 years, he noted that:

"The green policy for beautification has helped to reduce the incidence of street crimes as these once unused open spaces were hideouts for criminals. This policy is opening up new areas by decongesting the city centre and increasing development in the hinterlands."

\subsection{Influences and actors orienting current adaptation and risk management regimes}

\subsubsection{Leadership, institutions and inequality: as drivers of transition}

The Lagos State government was considered the most important actor influencing contemporary adaptation and risk management in the city, although the role of the media, city officials, civil society and businesses were also acknowledged by respondents (Figure 2). Following the transition of government from military to democratic regime in 1999, the State government adopted a vision of a 'prosperous, secure, greener and cleaner Lagos' consistent with the manifesto of the succeeding ruling party Action Congress of Nigeria (ACN). Starting from Tinubu 
I Ajibade et al.

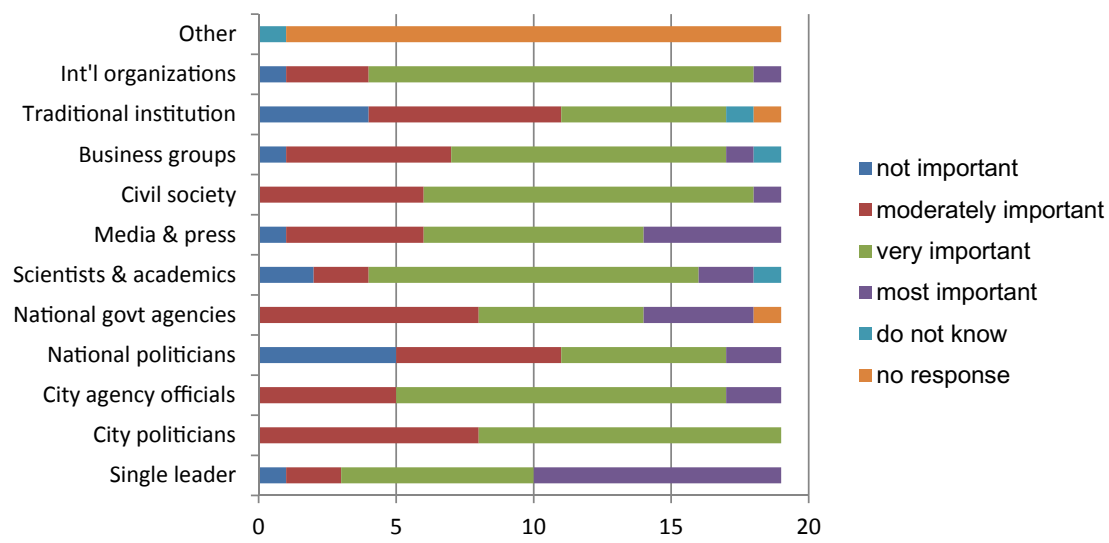

Figure 2. Actors Influencing the Current Adaptation Pathway

and more robustly under the leadership of Fashola (2007-2015), Lagos developed a three-pronged adaptation strategy that straddles between resistance and resilience. These strategies included greening and beautification, investment in grey infrastructure, and institutional policy changes. The greening and beautification strategy in line with the environmental vision of a flood-free, hygienic, greener and healthier Lagos was consistent with Goal 7 of the former Millennium Development Goals (MDG) and Goal 11 of the recent Sustainable Development Goals (SDG). The green initiative involves minimizing environmental degradation by restoring land resources, and creating livable spaces for Lagosians through tree planting, landscaping, road and sidewalks sweeping, firefighting, improved transportation and solid waste management, and establishment of parks. In the last 7 years, over five million trees were planted and 196 parks established across the city. This has had positive effects on air quality and aesthetics in the city and in combating street crimes. There were also add-on economic benefits such as boost for small enterprises (especially horticulturists and florists) and job creation for over 4,000 laborers (Kuris 2014).

Fashola's green strategy has received commendation both nationally and internationally but its implementation was criticized as top-down and autocratic. This was because it allowed little space for community participation and public dialogue. For instance, tree felling was criminalized without consultation with households and communities dependent on firewood as their main source of energy. Some experts also pointed out that the street beautification and greening initiatives did not alleviate the suffering of people in poorer districts. Neither did it provide the kinds of safety net and social protection that vulnerable groups needed in the face of disaster risk. 
A community chairman from a low-income area in Lagos said:

"Tree planting by the government is not enough. With regards to flooding, some areas, like Ikorodu, are heavily flooded. My personal views are based on the fact that the government is not meeting my personal expectations. However, government can be seen to be making effort in planting of trees but this is not enough."

The above statement suggests that the green adaptation program in Lagos was not fully linked to citizen's development aspirations and needs.

A second adaptation strategy embarked upon by the Lagos State government was the utilization of contemporary risk management strategies (such as early warning signals, establishment of tidal gauge stations and dissemination of daily meteorological reports) and the renewal of grey infrastructure. The latter included, investment in shoreline protection, construction and declogging of drainage systems and canals, as well slum clearance and demolition. For example, in 2013, the government demolished over 226 structures and forcibly evicted 9,000 people from Badia East as part of a World Bank-funded urban renewal project (Huffington post 2014). This frenzy of construction and demolition was often met with community resistance as citizens saw themselves marginalized or dispossessed by the government's rush to overhaul city infrastructure (Kuris 2014). While slum clearance does show the close tie between risk management and development, the experience in Lagos is oriented towards protecting the city's development profile, and not in enhancing coping capacity amongst the poor and those at risk. Forced relocation has been deployed in Lagos since the 1930s and was adopted by the Colonial Government to control the spread of bubonic plague that ravaged the city between 1923 and 1930 (Olukoju 1993). Its political implication, similar to the colonial era, is of a necessary purification effect - removing the 'bad' city so that the 'good' city can thrive (Reghezza-Zitt et al. 2012). In other words, urban renewal served as a justification to apply old modernization strategies to solve a 21st century development-climate risk problem. The chances of this strategy succeeding are limited since it does not address the root causes of risk and vulnerability but rather magnified and intensified their effect on the newly dispossessed populations.

The institutional and organizational reforms of the Fashola leadership were the niche for the radical innovation of the administration. The governor created new environmental legislations and policies, established implementing ministries and agencies and equipped them with funds and power to carry forward service delivery in areas such as emergency response, solid waste management, flood prevention, and greening and city beautification. Among those created were Ministry 
of Waterfront and Infrastructures, Ministry of Special Duties, Lagos State Safety Commission, Lagos State Emergency Management Agency, Lagos State Building Control Agency, Emergency Flood Abatement Department and Lagos State Parks and Gardens Agency (LASPARK). The Ministry of Environment as well as the Lagos Waste Management Authority and Lagos State Environmental Protection Agency were also revitalized with increased budgetary allocation and support. These special agencies developed norms and rules to regulate citizens' conduct and behavior and imposed fines for violations. LASPARK's obligation, for example, is to implement the greening policy of the State and also re-awaken the consciousness of citizens to the importance of a 'greened' environment including how a green environment can serve as a cost-effective approach to managing weather impacts and flooding while delivering other environmental, social and economic benefits. LASPARK also created laws that rendered certain actions punishable such as polluting, defecating and refuse dumping in parks and gardens. It is unclear if these new sanitary laws and infrastructure considerably improved citizens' access to the city's services. Without this, a pro-green agenda may quickly become a socially repressive one.

In addition to setting up institutions and norms, the Lagos State government developed strategic plans to link climate mitigation and adaptation directly to broader sustainability initiatives. First was the Lagos State Climate Change Policy (LAS-CCP 2012 - 2014) which was developed to assist the state to engage in a more strategic and cooperative approach to climate change impacts, maximize potential benefits, and take advantage of existing instruments such as the Clean Development Mechanism (CDM) and framework for reducing emissions from deforestation and degradation (REDD). The LAS-CCP further sought to provide an integrated method of reducing social vulnerability while enhancing the capacities of relevant stakeholders to implement measures that can help set the state on a path to energy efficiency and low-carbon economy without compromising short-term competitiveness (LAS-CCP 2012-2014). The second was the Lagos State Climate Change Adaptation Strategy (LAS-CCAS 2012) which aimed to reinforce actions such as disaster risk management and flood control already being taken by the state to address climatic extremes and to build resilience. LAS-CCP and LASCCAS both highlight the importance of mainstreaming climate change adaptation and mitigation into the state's development plans. An example of the State's climate change mitigation project is the rapid-bus transit system (BRT) which helped to improve transportation and reduce greenhouse emissions.

A Knowledge Coalition and Stakeholders Conference Forum on the environment and climate change were also formed by the Fashola administration in 2009 
with the launching of the Lagos International Climate Change Summit. This brought together a wide range of local, regional and international researchers, practitioners and climate change experts including members of the International Council for Local Environmental Initiatives (ICLEI) (the leading global network of local governments for sustainability). The summit has grown since then and its seventh meeting was held in 2015. Individuals and corporate organizations in Lagos participated in the conference with some partnering with government to reduce impacts of flooding, storm surges and potential sea level rise.

It is through these strategies, policies, institutions and stakeholder networks that the current constellation and regime on risk management and adaptation in Lagos has been established and stabilized.

\subsubsection{Influences on current adaptation endeavor}

City political priorities and business concerns have had the largest influences on the current resistance regime and the pro-green approach to adaptation in Lagos (Figure 3). Participants noted that while tensions between the Federal and Lagos State governments have led to reduced institutional and financial support for the city, the ruling AC party, both under Tinubu and Fashola administration, generated tax revenue to fund service delivery and infrastructural development. The State government over time have relied less on Federal allocation and more on internally generated revenues through taxes, land-use charges, sales tax, bonds, joint-ventures with private sectors, and to some extent development assistance. Internally generated revenue in Lagos has been rising since 1999. 'It rose from USD \$69 million a month in 1999 to $\$ 93$ million in 2008 and was more than $\$ 99$ million in 2010. It is expected to reach $\$ 160$ million in 2020' (Filani 2011). Businesses in the

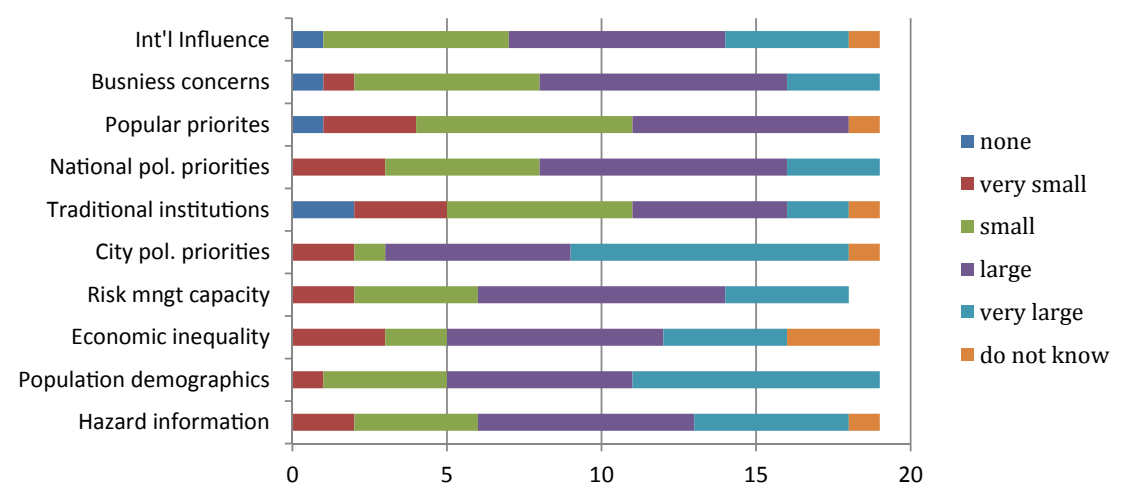

Figure 3. Factors Influencing the Current Adaptation Pathway 
city have been a major source of the internal revenue and have also been actively involved in the city's risk management and adaptation plans. For example, financial institutions were involved in the city beautification and greening projects. Private organizations also partnered with government on waste collection and disposal.

\subsection{Is there evidence that practitioners desire transition to a new risk management pathway?}

To help identify how close contemporary regimes may be to transition, interviewees were presented with four simple scenarios for a 20 year future: (1) a doubling of flood and heat wave hazard; (2) a doubling of the population over 65, in addition to increased hazard; (3) a doubling of the population living in poverty, in addition to aging and increased hazard; (4) a halving of risk management capacity in addition to increased poverty, aging and hazard. These scenarios were generated for use in sister studies in Kolkata, London, New York and Tokyo and so were purposefully kept simple to allow scope for comparison. Figure 4 shows the number of respondents who felt each scenario would require a significant revision of contemporary disaster risk management in Lagos. Of 19 respondents, almost half identified a need for change with increased hazards, signifying the fragility of the contemporary regime. Votes for reform increased with higher levels of vulnerability.

Respondents were also asked to describe the future regime they expected the city might arrive at by 2035 given the preceding discussion of development trends, leadership and risk. Figure 5 compares respondents' description of the contemporary regime with their best estimates of future status. Many respondents expected continuity of a resistance regime. This was accompanied by a reorientation towards

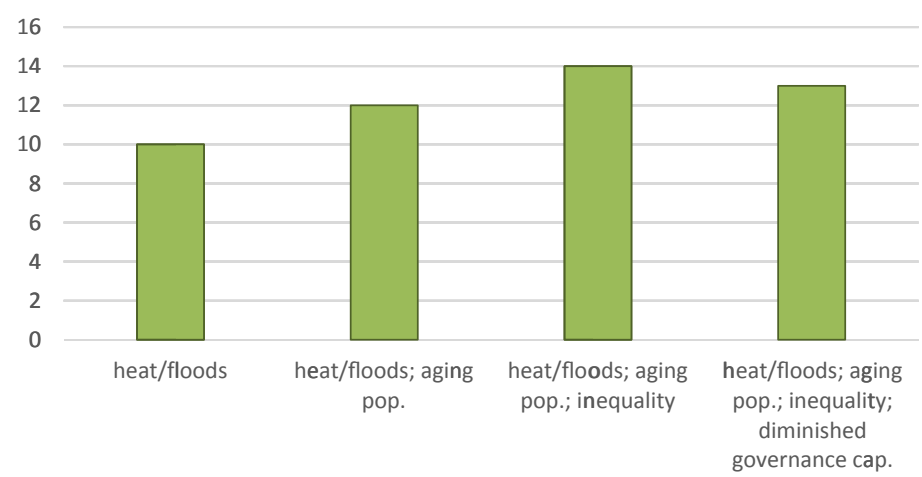

Figure 4. Triggers for Transition in Risk Management 

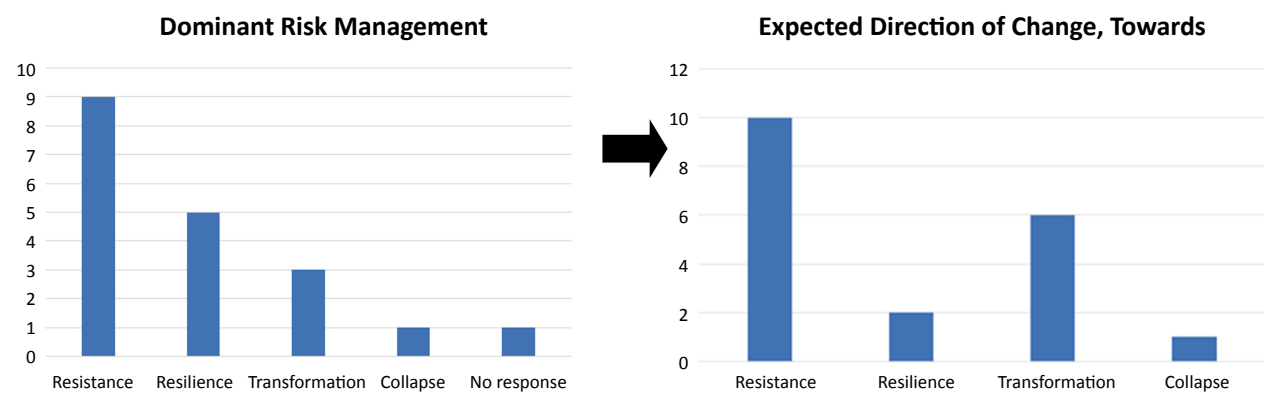

Figure 5. Contemporary and Anticipated City Risk Management Regimes

transformation (i.e., risk management that aims to tackle risks by reducing root causes in development failure). Resilience declined in importance as the regime is stressed by the two poles of resistance (protect development) and transformation (reform development). In either case it is clear in Lagos that development is a driver of risk management. There is little appetite for development to change at the margins as a mechanism for future risk management. The director of a government environmental protection agency, who expected the current resistance regime to persist, stated that:

"The current planning and policy are not too bad hence we are not planning to change the current planning/policy approach rather we want to boost what we already have and improve on implementation"

A community development chairman who held a different view in which transformation is considered a desired stabilizing regime expressed that:

"If the city is stable in terms of hazard/risk management it will lead to higher economic activities and stability. Furthermore, employment would be provided to restive youth and peace and security from terrorism and street crimes would be achieved."

By far, the greatest concern for most respondents was policy consistency, which they viewed as important in managing climatic extremes and uncertainties as well as development challenges in Lagos. Participants were unsure whether the new Lagos State government under Akinwunmi Ambode would build on current adaptation and development gains while also addressing perennial inadequacies in housing, infrastructure, land-use planning and city management. A policy maker concerned about whether the successes of the Fashola Administration would be 
maintained and whether a transition towards a transformative regime could be realized said:

"I expect that there should be continuity based on the fact that the new government is from the same political party as the previous. Over the past 16 years, the policy has been stable with climate change, transportation and combating street crime. Presently, there is policy confusion as the new government is yet to define in clear terms the direction of governance."

\subsection{Is transition imperative in Lagos, how can it be enabled or constrained?}

\subsubsection{Reactive planning and a lack of community participation}

Many respondents did not consider a regime transition as imperative because they perceived the changes that had occurred in the last 16 years as significant enough. Respondents described a city that was transitioning from collapse to a resistance and conceivably a resilient regime. However, the changes made were engineered through a top-down political process and legitimized through the institutions of the state. Quite often deliberative forums and community participation were neglected in favour of centralized institutional approaches. These approaches did not attempt to reconcile distributional and procedural justice in the structural interventions meant to reduce future risks and broaden adaptation opportunities. The transition that occurred over the last two decades were mainly reactive; they were triggered by past extreme events and its interaction with land-use pressure and urban development challenges. For instance, it was not until after the July 2008 and July 2011 flooding that the maintenance of drainage channels, de-silting of canals and physical planning became a priority, however, implementation and monitoring were short-lived. A researcher in urban planning mentioned that:

"Natural disasters such as flooding and sea surges are not given attention. I believe that priorities are not well ordered. Priorities are given to issues as they arise. If there is no current disaster whether natural or social, much is not done."

Condemning the reactive approach to risk management, a city planner said:

"The State should be more proactive rather than reactive. Response to emergencies is rather slow. Effective communication of hazards and early warning signs should be done in the local languages of the people through the use of media and the press" 


\subsubsection{The science-policy gap}

The science-policy interphase is a crucial area where capacity is needed to boost the current transition trajectory. Many respondents identified the gaps in science and technology together with urban development pressures as the most important factors constraining strategic transition towards transformation (Figure 6). Lagos has no formal database on hazard information besides records of meteorological data. There are also fewer funding institutions for research and capacity building. To ascertain risk, planners and policy makers have in time past relied on hazard information from media sources but these are not always accurate or reliable. To address this knowledge gap, participants called for improvement in vulnerability and capacity assessment, data gathering and storage, and risk analysis and communication. Improvement in these areas can catalyze efforts possibly towards transformation, as these elements are the bedrock upon which an informed risk management decision and policy are made.

\subsection{Barriers to transformative regime transition}

A number of barriers were identified as obstacles to a transformative and proactive risk management regime in Lagos. These included the lack of political will among city officials, partisan politics, political interferences in ministries activities, and the effect of the electoral cycle. The Fashola government had a strong interest in sustainable environmental management and did put in place measures for effective response to risk reduction. However, leaders and heads of ministries and agencies specifically tasked with risk management obligations did not always carry through with the governor's enthusiasm. The lack of coordination among these agencies

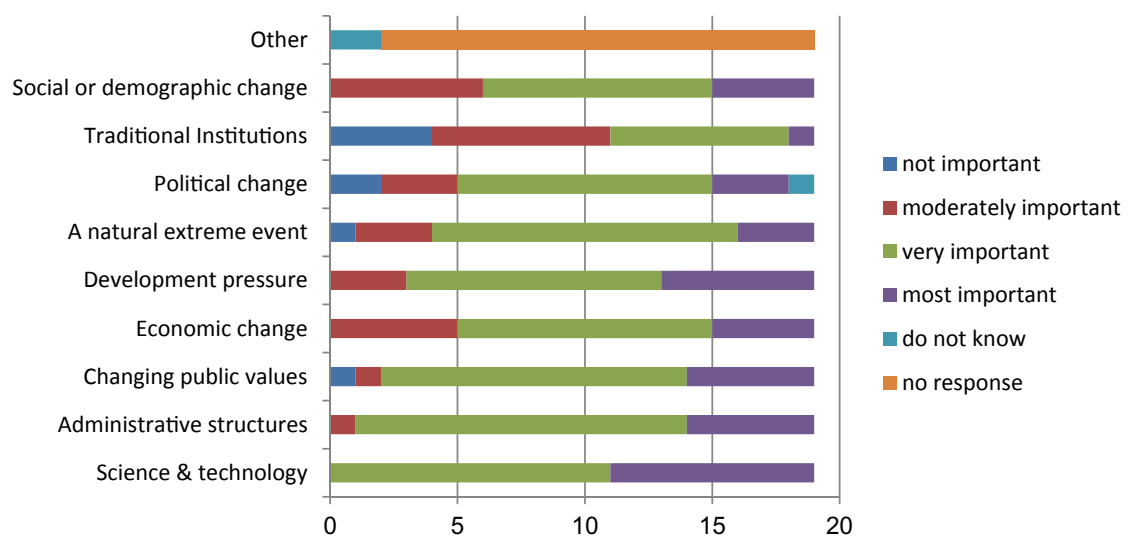

Figure 6. Influences on Regime Transition 
created a disjointed and fragmented approach to risk reduction and adaptation planning. Patronage, corruption and interference from political 'god fathers' also created tension that led city agency officials to be selective about which communities get prioritized and to which districts emergency resources were directed. A respondent from the health, safety and environment office, said this about political interference:

"Interference of politics in day to day activities of the ministries, departments and agencies is a big issue. Also, the change in government processes cause distractions and truncates consolidation of existing policies, projects, and programs”.

Electoral cycle has had the effect of undermining consistency in strategic development and leadership in urban management. This included breaking momentum in on-going transitions; for example the new governor did not seek to build on the progress of his predecessor but rather adopted and implemented new policies and legacies of his own. This is a crucial barrier for processes like transition that take time (requiring more than one electoral term) and are change oriented. A city planner speaking on the effects of electoral cycle said:

"Political will by the state government is the major driver that informs the policy direction of the state. The Fashola Administration (2007-2015) was focused on the environment, security, transportation and food security but the Ambode Administration (2015-Present) is focused on security and job creation"

Furthermore, economic instability and the lack of finance are major barriers that can affect the speed of transition. Nigeria still relies heavily on oil for well over 70 percent of its national revenue. The stunning decline in global oil prices from a peak of \$115 per barrel in June 2014 to under \$35 at the end of February in 2016 (WEF 2016) has hit the country hard causing economic instability, falling currency values, reduced spending on infrastructure, and spikes in prices of food and household items. Lagos, the economic hub of the country is not immune to these impacts. Reduced oil and gas export in 2015 affected recurrent and capital expenditure, triggered layoffs mostly in the private sector and owed salaries of more than 8 months in the state civil service (Vanguard Newspaper 2016). The drop in government revenue has also interrupted a number of adaptation and development projects. Cuts in social services and increased taxation, which are the usual fiscal responses to such economic crisis could affect the adaptive capacity of the poor and undermine autonomous efforts taken by individuals to build resilience against climatic extremes. These problems amply demonstrate the need for the Federal and 
Lagos State governments to promote economic resilience through diversification of the local economy and through policy-shift to low-emissions development including increased investment in renewable energy, eco-tourism, and agriculture. An urban planner who suggested alternative sources of revenue generation to boost and sustain adaptation said that:

"Due to the present economic crisis in the country there is an ongoing decline in government resources. Therefore there is a need for the government to partner with the private sector and civil society so that they can support the government to generate funds for projects and susbtainably manage the scarce resources to achieve maximum impact especially at the grassroots level."

\section{Conclusion}

Sustainability transition is an unrealized endeavor in Lagos. The city has transitioned from collapse in the past decade advancing risk management and adaptation practices, however, challenges remain with maintaining past gains and transitioning towards a more resilient or transformative society. This requires continuous evolution of city governance and administration to proactively address the intersecting problems of population pressure, housing shortages, street crime, climatic hazards and economic stagnation. The Green Policy initiative and its institutionalization, is perhaps the innovation most evocative of transition in the city's adaptation-development nexus. This has demonstrated that Lagos can administer a strategic and integrated policy agenda that combines risk reduction with environmental enhancement and climate change mitigation. Still, critics of the programme claim its success has distracted planners from more far-reaching and socially progressive agendas of change. The initiative has not been able to address the root causes of vulnerability and unequal adaptive capacity among Lagosians. Nonetheless, additional reforms that have taken place in waste management, transportation, early warning and security are commendable especially for a city with a history of administrative and environmental dysfunction.

The current study provided a voice for respondents who expressed an overriding desire for increased rule-of-law and for rigorous administrative procedures at the heart of any revisioning of Lagos' risk management and climate change adaptation approach. The stakes are high in Lagos. Many poor residents are disenchanted with and marginalized from public life; violence and crime are a significant pressure on wellbeing and economic development. In this context a current regime oriented to resistance (i.e., protecting development gains and existing policies and processes) was a least bad choice. That respondents considered a future could also include 
transformative approaches that would address development failures as root causes of risk - is a vote for a progressive future. It is notable that collapse (i.e., no strategic planning) was only minimally present in discussions of the contemporary period or future. It is also notable that resilience was not an expected future state; perhaps respondents lacked confidence in the ability of government to deliver its more nuanced and flexible development-risk management relationship. The juxtaposition of resistance and transformation can perhaps best be interpreted as a preference for a 'development first' agenda, where risk management can be enhanced to protect core development activities (e.g., policing land-use and maintaining critical infrastructure standards). This is consistent with respondents expressed desire for a more structured and accountable city governance and administration.

\section{Acknowledgment}

Reported in this paper was undertaken as part of the Belmont Forum funded Transformation and Resilience on Urban Coasts (TRUC) project. This project was supported by Japan Society for the Promotion of Science, the UK Natural Environment Research Council and Economic and Social Research Council (NE/ L008971/1) the German Research Foundation (GZ: BI 1655/1-1), The Ministry of Earth Sciences, Government of India (MoES/01-CZM/Truc/2013) US National Science Foundation (ICER-1342966) and Social Science and Humanities Research Council, Canada (756-2014-0294).

\section{References}

Ajibade, I and McBean G (2014). Climate extremes and housing rights: A political ecology of impacts, early warning and adaptation constraints in Lagos slum communities. Geoforum, 55: 76-86.

Ajibade, I, McBean G and Bezner-Kerr R (2013). Urban flooding in Lagos, Nigeria: Patterns of vulnerability and resilience among women. Global Environmental Change, 23(6): 1714-1725.

Anguelovski, I, Shi L, Chu E, Gallagher D, Goh K, Lamb Z and Teicher H (2016). Equity impacts of urban land use planning for climate adaptation critical perspectives from the Global North and South. Journal of Planning Education and Research, doi: 10.1177/0739456X16645166.

Awosika, LF, Dublin-Green CO, Folorunsho R, Adekoya EA, Adekanmbi MA and JimSaiki J (2000). Study of main drainage channels of Victoria and Ikoyi Islands in Lagos Nigeria and their response to tidal and sea level changes. CSI-UNESCO Special Report.

Bridge, G, Bouzarovski S, Bradshaw M and Eyre N (2013). Geographies of energy transition: Space, place and the low-carbon economy. Energy Policy, 53: 331-340. 
Bulkeley, H, Broto VC, Hodson M and Marvin S (Eds.). (2010). Cities and Low Carbon Transitions. UK: Routledge.

Ekanade, O, Ayanlade A and Orimoogunje OI (2011). Climate change impacts on coastal urban settlements in Nigeria. Interdisciplinary Environmental Review, 12(1): 48-62.

Filani, MO (2011). A City in Transition: Vision, Reform, and Growth in Lagos, Nigeria. Cities Alliance United Cities, P107221.

Garschagen, M and Birkmann M (2017). A new scenario method for analytically and normatively capturing the adaptation-development-nexus in cities through co-production, forthcoming.

Garschagen, M, Pelling M, Solecki W, Birkmann J, Agboola J, Narayanan P and Ajibade I (2017). Future in the making: Participatory scenario development on climate risk pathways and transformation policies in coastal megacities, forthcoming.

Geels, FW (2002). Technological transitions as evolutionary reconfiguration processes: A multi-level perspective and a case-study. Research Policy, 31(8): 1257-1274.

Geels, FW (2010). Ontologies, socio-technical transitions (to sustainability), and the multilevel perspective. Research Policy, 39(4): 495-510.

Geels, FW (2011). The multi-level perspective on sustainability transitions: Responses to seven criticisms. Environmental Innovation and Societal Transitions, 1(1): 24-40.

Geels, FW and Schot J (2007). Typology of socio-technical transition pathways. Research Policy, 36(3): 399-417.

Hekkert, MP, Suurs RA, Negro SO, Kuhlmann S and Smits RE (2007). Functions of innovation systems: A new approach for analysing technological change. Technological Forecasting and Social Change, 74(4): 413-432.

Heinrich Böll Foundation Nigeria (2012). Eko Atlantic: The dream of a new model city struggling with transparency, good governance and negative environmental impacts. http://www.ng.boell.org/downloads/Eko_Atlantic_Project_-_Fact_Sheet.pdf [March 2, 2015].

Hewitt, K (1983). Interpretations of Calamity from the Viewpoint of Human Ecology. Australia: Allen \& Unwin.

Jefferson, M (2008). Accelerating the transition to sustainable energy systems. Energy Policy, 36(11): 4116-4125.

Jones, RN and Preston BL (2011). Adaptation and risk management. Wiley Interdisciplinary Reviews: Climate Change, 2(2): 296-308.

Kemp, R, Loorbach D and Rotmans J (2007). Transition management as a model for managing processes of co-evolution towards sustainable development. The International Journal of Sustainable Development \& World Ecology, 14(1): 78-91.

Kjellstrom, T, Butler AJ, Lucas RM and Bonita R (2010). Public health impact of global heating due to climate change: Potential effects on chronic non-communicable diseases. International Journal of Public Health, 55(2): 97-103.

Lagos State Climate Change Policy (LAS-CCP) (2012) Climate Change Policy 2012-14. Retrieved January 20, 2013, from http://developmentdiaries.com/wp-content/ uploads/2013/03/Lagos-State-Climate-Policy-First-Draft_27.03.2012.pdf

Lagos State Climate Change Adaptation Strategy (LAS-CCAS) (2012). Towards a Lagos state climate change adaptation strategy, prepared for the Commissioner for Environment, Lagos State, by the Building Nigeria's Response to Climate Change 
I Ajibade et al.

(BNRCC) project. Retrieved January 18, 2013, from http://nigeriaclimatechange.org/ docs/IasAug2012.pdf

Leichenko, R (2011). Climate change and urban resilience. Current Opinion in Environmental Sustainability, 3(3): 164-168.

Loorbach, D (2010). Transition management for sustainable development: A prescriptive, complexity-based governance framework. Governance, 23(1): 161-183.

Matyas, D and Pelling M (2015). Positioning resilience for 2015: The role of resistance, incremental adjustment and transformation in disaster risk management policy. Disasters, 39: s1-s18.

Moser, SC and Ekstrom JA (2010). A framework to diagnose barriers to climate change adaptation. Proceedings of the National Academy of Sciences, 107(51): 2202622031.

Newell, P and Mulvaney D (2013). The political economy of the 'just transition'. The Geographical Journal, 179(2): 132-140.

Nwilo, PC (1997). Managing the impacts of storm surges on Victoria Island, Lagos, Nigeria. Proceedings of the Conference Destructive Water: Water-Caused Natural Disasters, their Abatement and Control. June 1996, Anaheim, California. IAHS Publications-Series of Proceedings and Reports-Intern Association Hydrological Sciences, No. 239, pp. 325-330.

O’Brien, K (2012). Global environmental change II From adaptation to deliberate transformation. Progress in Human Geography, 36(5): 667-676.

O'Keefe, P, Westgate K and Wisner B (1976). Taking the naturalness out of natural disasters. Nature, 260(5552): 566-567.

Olaniyan, E and Afiesimama EA (2003). Understanding Ocean Surges and Possible Signals over the Nigerian Coast: A Case Study of the Victoria Island Bar-Beach Lagos.

Olukoju, A (1993). Population pressure, housing and sanitation in West Africa's Premier Port-City: Lagos, 1900-1939. The Great Circle, 15(2): 91-106.

Pelling, M (2010). Adaptation to Climate Change: From Resilience to Transformation. UK: Routledge.

Pelling, M, Abeling T and Garschagen M (2017). Emergence and Transition in London's Climate Change Adaptation Pathways. Journal of Extreme Events Change, forthcoming.

Pelling, M, O’Brien K and Matyas D (2015). Adaptation and transformation. Climatic Change, 133(1): 113-127.

Raven, RP and Geels FW (2010). Socio-cognitive evolution in niche development: Comparative analysis of biogas development in Denmark and the Netherlands (1973-2004). Technovation, 30(2): 87-99.

Reghezza-Zitt, M, Rufat SS, Djament-Tran AG, Le Blanc A and Lhomme SS (2012). What resilience is not: Uses and abuses. Cybergeo: European Journal of Geography.

Rosenzweig, C, WD Solecki, SA Hammer and S Mehrotra (Eds.) (2011). Climate Change and Cities: First Assessment Report of the Urban Climate Change Research Network. Cambridge, UK: Cambridge University Press.

Schipper, L and Pelling M (2006). Disaster risk, climate change and international development: Scope and challenges for integration, Disasters 30(1): 19-38. 
Smith, A, Voß JP and Grin J (2010). Innovation studies and sustainability transitions: The allure of the multi-level perspective and its challenges. Research Policy, 39(4): 435-448.

Solecki W, Pelling M and Garschagen M (2017). Transitions between risk management regimes in megacities. Ecology and Society, in review.

Swilling, M and Annecke E (2010). Just Transitions. NY: University of Cape Town Press. Taylor, M (2014). The Political Ecology of Climate Change Adaptation. NY: Routledge.

Tschakert, P, Tuana N, Westskog H, Koelle B and Afrika A (2016). T CHANGE: The role of values and visioning in transformation science. Current Opinion in Environmental Sustainability, 20: 21-25.

UNDP (2004) Reducing disaster risk: A challenge for development. A Global Report, New York: UNDP, pp. 145.

Vanguard Newspaper (2016). New Year oil price crash: Nigerians as victims. Omonisa O (ed.). http://www.vanguardngr.com/2016/01/new-year-oil-price-crash-nigerians-asvictims/.

World Economic Forum (WEF) (2016). What's behind the drop in oil prices? https://www. weforum.org/agenda/2016/03/what-s-behind-the-drop-in-oil- prices.

Wise, RM, Fazey I, Smith MS, Park SE, Eakin HC, van Garderen EA and Campbell B (2014). Reconceptualising adaptation to climate change as part of pathways of change and response. Global Environmental Change, 28: 325-336.

Wisner, B, Blaikie P, Cannon T and Davis I (2004). At Risk: Natural Hazards, People's Vulnerability and Disasters, 2nd Edition. NY: Routledge, pp. 1-127.

WHO (2009). Improving public health responses to extreme weather heat-waves EuroHeat. Copenhagen: WHO Regional Office for Europe.

World Bank (2012). Inclusive Green Growth: The Pathway to Sustainable Development. Washington, DC: World Bank Publications. 